\title{
Landslide Zoning in Amir-Almoemenin (AS) Water Supply Pipeline Complex, North Khorasan
}

\author{
Bizhan Shirdel ${ }^{1}$, Ali Sorbi ${ }^{*}$, Ali Solgi ${ }^{2}$ \\ ${ }^{1}$ Department of Geology, Karaj Branch, Islamic Azad University, Karaj, Iran \\ ${ }^{2}$ Department of Geology, Science and Research Branch, Islamic Azad University, Tehran, Iran \\ Email: *ali_sorbi@kiau.ac.ir
}

Received 2 December 2015; accepted 16 January 2016; published 19 January 2016

Copyright (C) 2016 by authors and Scientific Research Publishing Inc.

This work is licensed under the Creative Commons Attribution International License (CC BY). http://creativecommons.org/licenses/by/4.0/

(c) (†) Open Access

\begin{abstract}
Landslide term is used for all mass movements on slopes, including falling, overturns and flow debris. Using the potential landslide hazard zonation, areas with high potential of landslide hazard can be detected and so prevent the landslide occurrence with providing appropriate solutions. In this study, the landslide hazard zonation along the water transmission lines of the AmirAlmomenin (AS) water supply complex has been done. Studied area is located at the western part of the Northern Khorasan (Bojnord). Study procedure includes the general geology survey, recognition of the most important effective parameters on the landslide phenomena (such as slope, lithology, faults and streams) and has been evaluated as basic maps. Then, each layer was validated based on the importance of the effective factors using the maps weighting method in ArcGis software. Finally, the studied area was zoned based on the landslide potential using the overlapping of the various layers. Final zonation map shows that the North, Northwestern and Median parts of the studied area have the highest landslide potential. These areas are included of Marl and red Marl and to some extend loss deposits with slopes between 14 to more of 50 degrees. Seemingly, faults (due to low occurrence) and streams (due to drought) have lower effect on the landslide potential. However, the degree of the slope and type of lithology are the most important parameters on the landslide potential, respectively.
\end{abstract}

\section{Keywords}

Landslide, Zoning, Amiralmoemenin Water Supply Pipeline, Mass Movements, Northern Khorasan

\footnotetext{
${ }^{*}$ Corresponding author.
} 


\section{Introduction}

Some parts of Iran with mountainous topography, high tectonic and seismic activity, various climatic and geological conditions, have suitable background for creation of the landslide. Therefore the mentioned features and conditions create some hazards, despite all benefits.

According to an initial estimation, about 500 billion financial damages are endured from landslides, per each year. Whereas this is the irreversible loss of natural resources which are not taken into account [1]. Data recorded by the Ministry of Agriculture show that until 2000 mass movement and landslide in the Iran, have been caused of the deaths of 162 people, destroyed 176 homes, financial losses of 1866 billion Rials, the destruction of 676 hectares of forest and destroyed 170 kilometers of roads and linear structure [2]. In damming construction field, landslide phenomena, considering the conditions and its properties, reduce the useful life of the dam or even failure of the dam with filling of the reservoir, or structural damaging.

In the South Khorasan province, due to specific lithology characteristic, tectonical situation and climatic condition, numerous landslides are occurred every year that sometimes is associated with the great human and financial losses (Figure 1). The cities of Bojnord and Shirvan are regions that almost every year, landslides in different dimensions are happened. The incidence of these events can be seen in the large mountainous and rural areas with the different damages on agricultural lands, residential homes, roads and the associated human and financial losses [3].

In an area in the Khorasan province, in order to pipe for water supplying (Figure 2), several studies have been done, which one of them was the evaluation of landslide risk in the area that studied in this paper.

Firstly, in this study, the effective factors on the landslide occurrence are evaluated in general. Then, these factors are evaluated in the studied area. Finally, based on the prepared landslide hazard zoning map, the high and low risk areas are detected and explained.

\section{Geological Setting}

The studied villages in the area are located in the Maneh-Salaghan and Bojnurd cities of the Northern Khorasan province $\left(37^{\circ} 33^{\prime} \mathrm{N}\right.$ to $37^{\circ} 43^{\prime} \mathrm{N}$ and $57^{\circ} 15^{\prime} \mathrm{E}$ to $\left.56^{\circ} 51^{\prime} \mathrm{E}\right)$. Figure 1 show location of the North Khorasan province in the Iran.

According to geological features (sedimentary and tectonic) Iran is divided into several zones. In the Sedimentary-tectonic zone of Iranian plate, North Khorasan province is located in the Kope-dagh zone (Figure 3 [4]). In the ongoing part, some characteristic of this zone has been expressed.

Paleozoic rocks in the studied area aren't exposed. Mesozoic rocks contain relatively thick sequence of limestone, marl and some terrigenous rocks. Source rocks and reservoir of Khangiran gas reserves in near area are part of Mesozoic sequences. Northern Khorasan Province has a changing climate due to its expanse, local and natural factors. The main reason for climate changes of this region is the interaction between different columns of air which enter the region from the west, southwest and northeast of this province. In addition, high mountains and depressed areas have significant effects on climate changes of the province; generally, Northern Khorasan Province has a temperate, alpine climate [4].

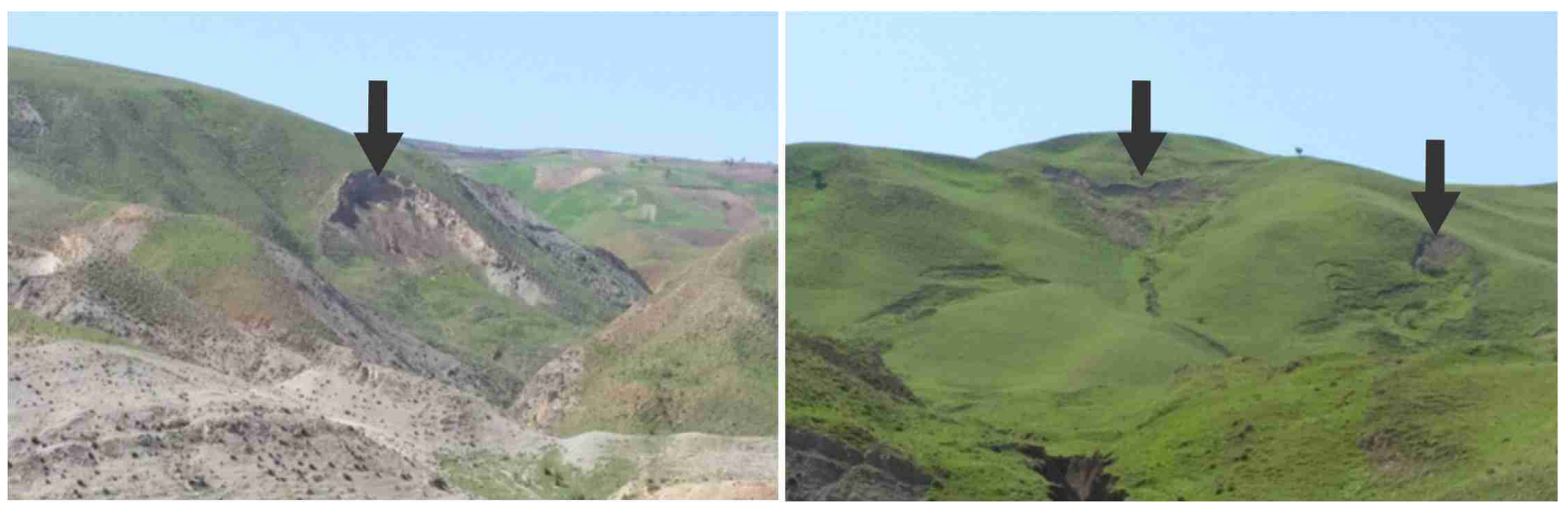

Figure 1. Some example of landslides in the study area. 

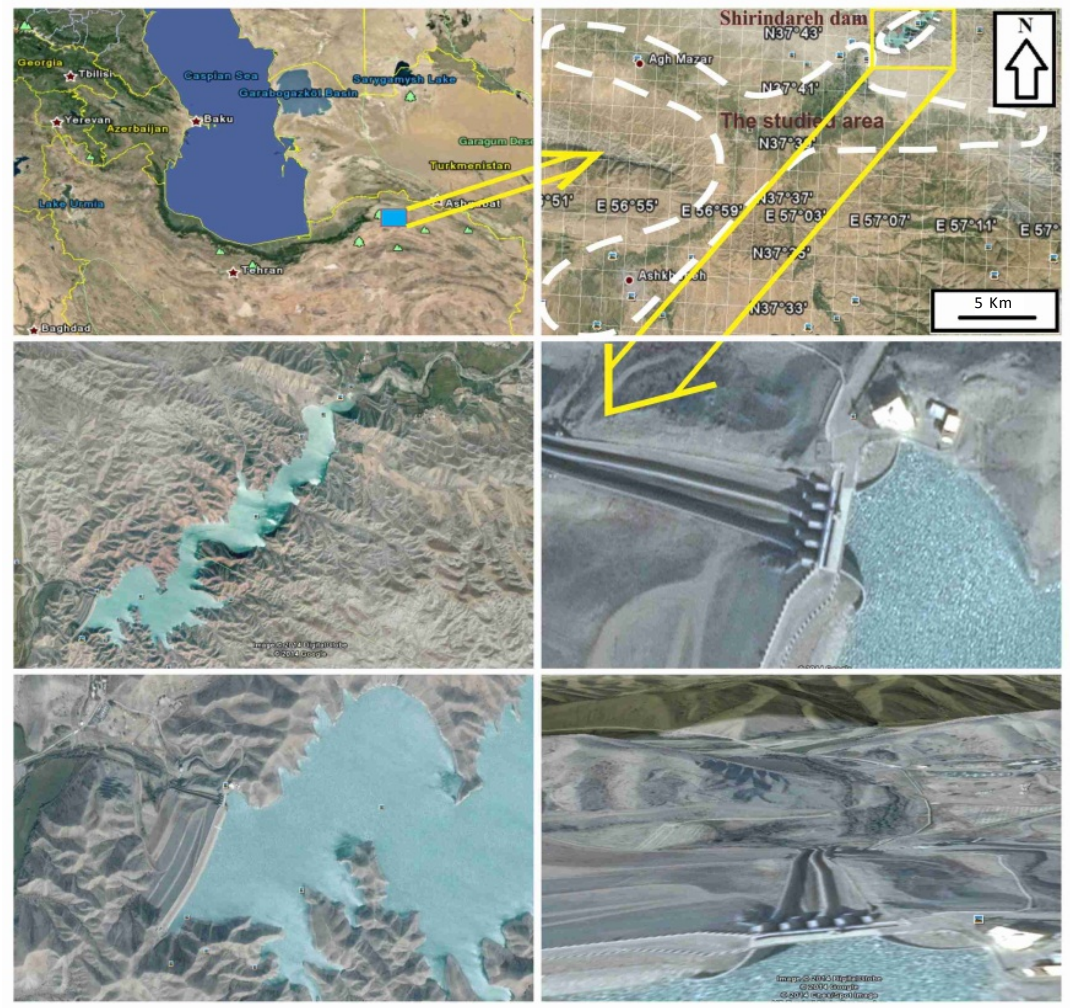

Figure 2. Satellite images of the area at different scales and also the Shirindareh dam to be the source of the water (images are from Google Earth).

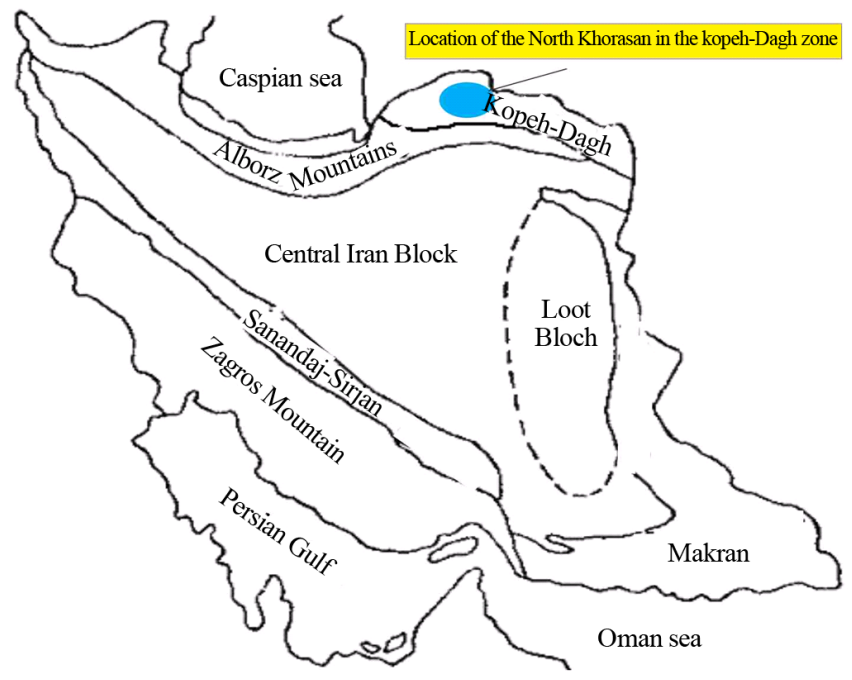

Figure 3. Tectonic zones map of Iran and location of North Khorasan [5].

Kope Dagh mountain ranges are located in the northern part of Khorasan (Iran) and Turkmenistan. This sedimentary basin occupies an extensive area in the North of Iran. Geologically point of view, it lies in northern margin of central Iran unit, Alborz unit and the southern edge of Touran plate in central Asia. This zone forms the northern end of Iranian part of the Alpine-Himalayan orogeny [6]. In this basin thick Tertiary-Mesozoic sediments (8000 $\mathrm{m}$ in Iran, 17,000 $\mathrm{m}$ in Turkmenistan) have been accumulated in a narrow sedimentary trough and have been intensely affected by the young alpine Neogene-Quaterner phases and were folded. Northern section of Kope Dagh ends to a basement related fault zone which delineates Touran plate boundary with Kope Dagh [6]. 


\section{Validation to Factors}

As mentioned above, in this study such as some studies in Iran ([7] [8]). The validation is carried out. Slope gradient and lithology type are the most important factors, respectively. Due to very low rain and drought, streams and drainage have low importance.

\section{Landslide Zoning in Amiralmoemenin (AS) Water Supply Pipeline Complex}

\subsection{Lithology}

As previously stated, attention to the lithology as one of the most important triggers in hillside motions is very necessary. Lithology role in the slope movements such as rockfall influenced by rock hardness and the weathering of rocks and cracks. The lithology reflects the characteristics of engineering geology and rock mechanics as well as the region. The adhesion properties and internal friction angle of the engineering properties of lithology are a lot of impact. For use of lithology as a layer, the lithology of area based on geological maps (geological maps with a scale of 1/250,000) was extracted and examined in the field observations and finally the lithology map was Digitized, and converted to the information layer (Figure 4).

Here into the classification and ranking of this factor is conducted by different researchers in different ways. But what is good for the climate of Iran seems more practical is [7]-[9]. So, rock units in the study area based on mentioned investigations are classified and validated which modified based on field observations (Figure 5) and properties of the area that included in final zoning map.

\subsection{Streams}

Most of the mass movement occurred after a heavy rainfall. This shows the importance drainage system in creation of landslide because they act as a flow path surface. Water flowing is a factor in improving preparedness of slope instability. In Figure 6 the main waterways of the region are drawn and Examples of the main streams in the study area showed in Figure 7.

\subsection{The Amount and Direction of Slope}

As mentioned in the affecting parameters causing instabilities section, the slope effect as one of the most effec-

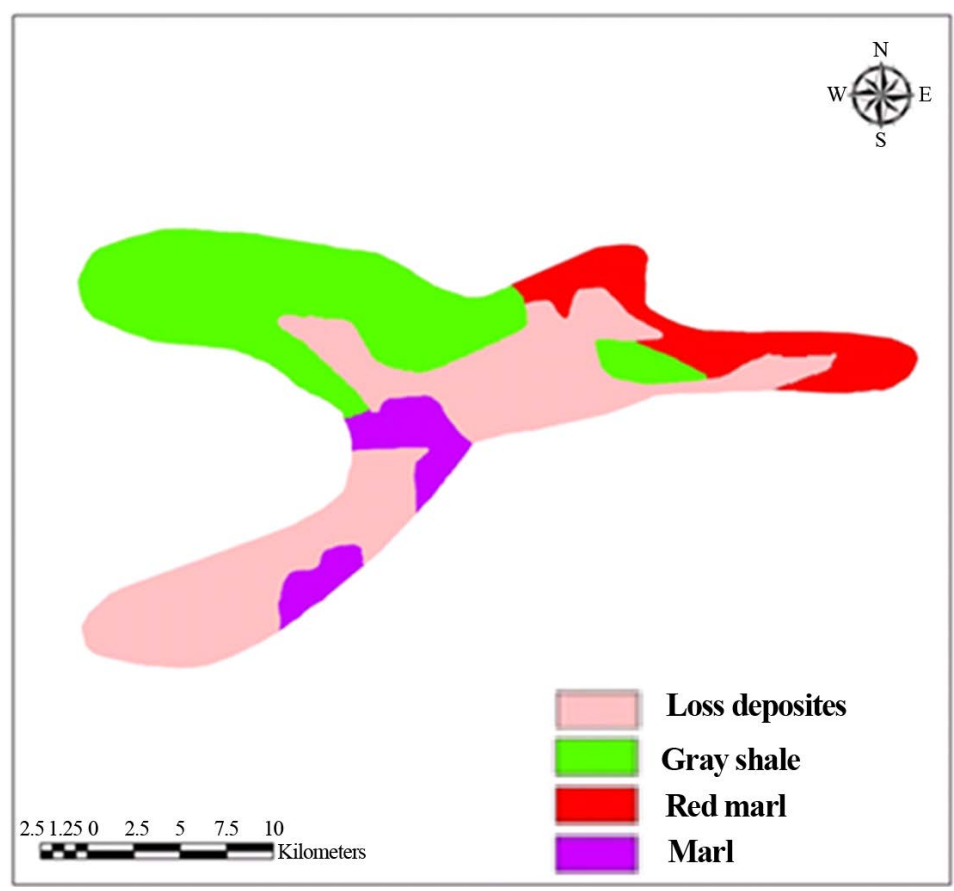

Figure 4. Validated distribution map of lithology units in the region. 

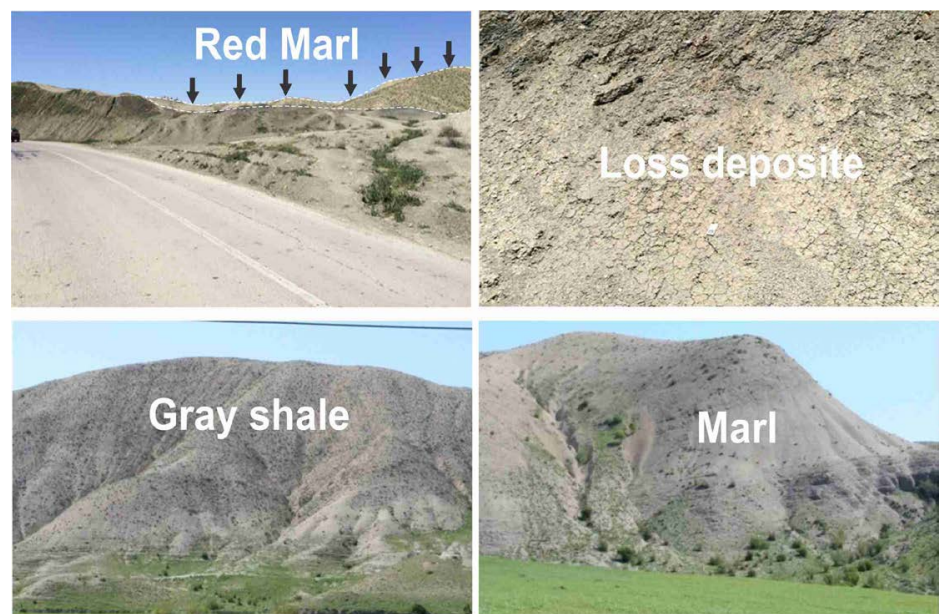

Figure 5. Field image of lithology unite in the studied area.

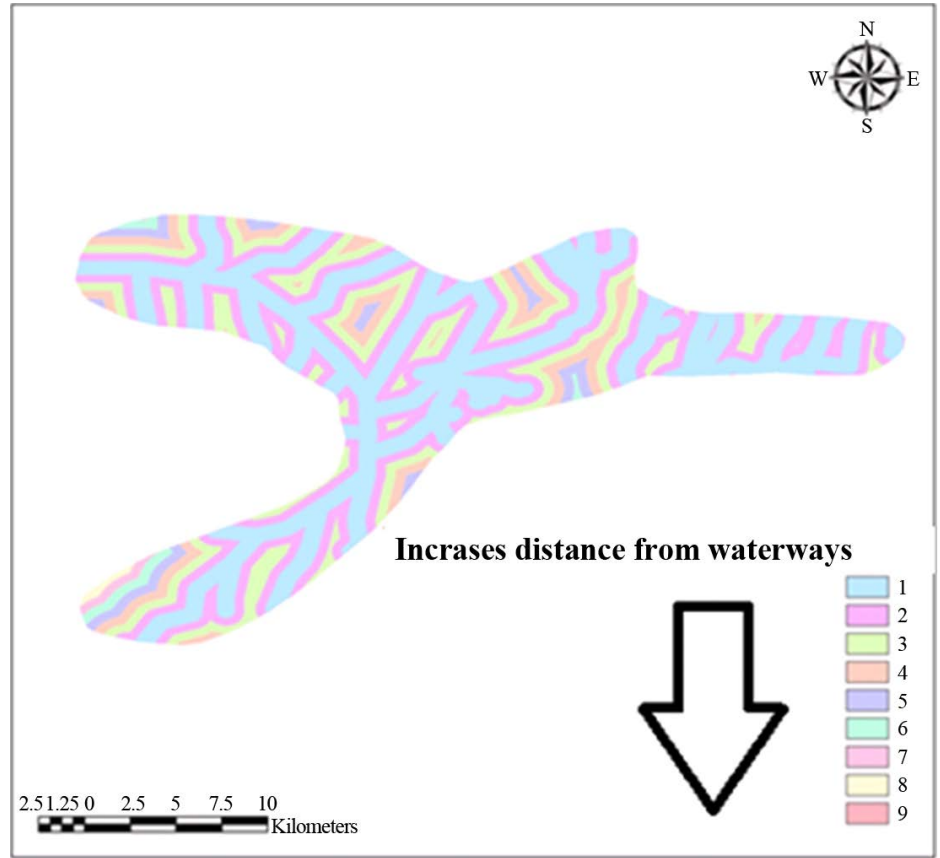

Figure 6. Validated main waterways map area.

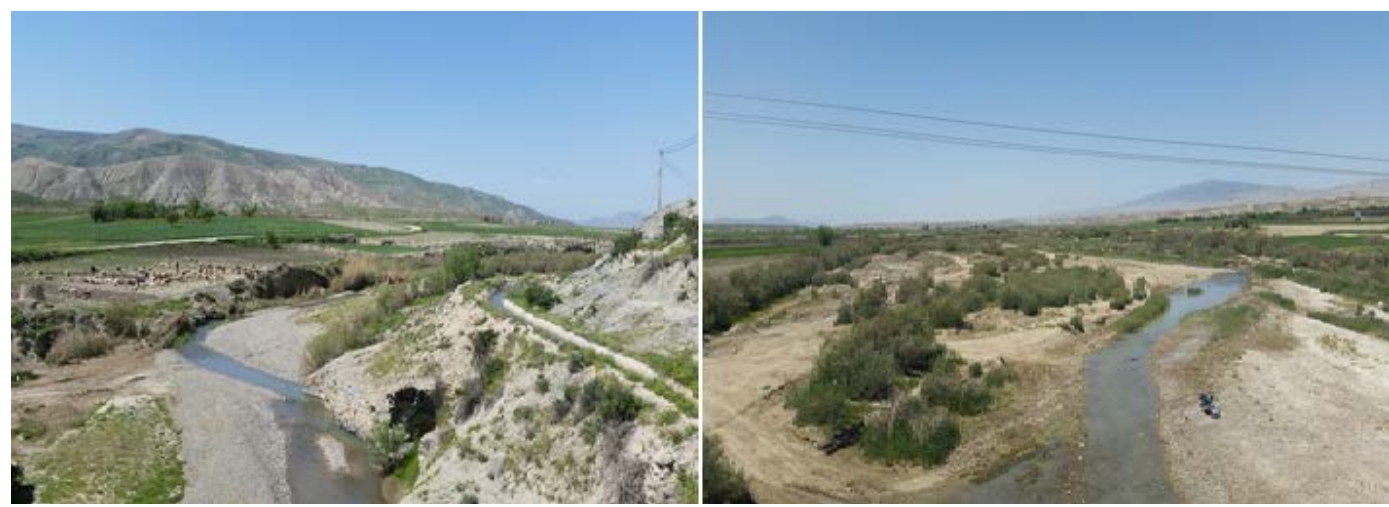

Figure 7. Examples of the main streams in the study area. 
tive factor in creation of instabilities is quite obvious. The slope layer (Figure 8) is prepared based on data from various maps of area (mainly topography and isopach maps) and also field observations. Here the slope is classified into five categories. Topographic map is used to prepare Tin and also for high precision of tin, several points on the same lines in height were used and then tin converted to slope.

Also in this study, after extraction of the slopes direction from Elevation Model the slopes were divided into 9 groups (Figure 9).

\subsection{Faults}

Faults are areas to release energy of earth and the release of energy can be seasoned and triggers landslide. Faults were extracted from geological maps and were validated with data on existing GIS databases and field observations have also been (Figure 10 and Figure 11).

Also in this study Joint study partly confined (Figure 12). It seems that in the studied region joints are more accumulates in place of fault and in other sectors are widespread. For this reason, the distribution of joint is not used as a layer.

\subsection{Roads}

As above mentioned, in mass movements such as landslides one of the affecting (but with low importance) factors are the road (Figure 13). Because during established the road gets rammed earth and underground water can easily move in the subsurface soil and increase the weight of the soil above the road, thus causing irritation of soil and creation of landslides.

\subsection{The Final Map of Landslide Hazard Zonation}

For the preparation of landslide hazard zonation in the region, the validation was carried out. The appointment to validation of the previous articles ([7] [8] [10]) and previous work done in the near area were used and Classical fuzzy logic methods were used for validation. In the final stage based on the importance of effective factor, each layer has to be validated individually. The minimum value of zero and a maximum of 10 are given to each layer (Figure 14).

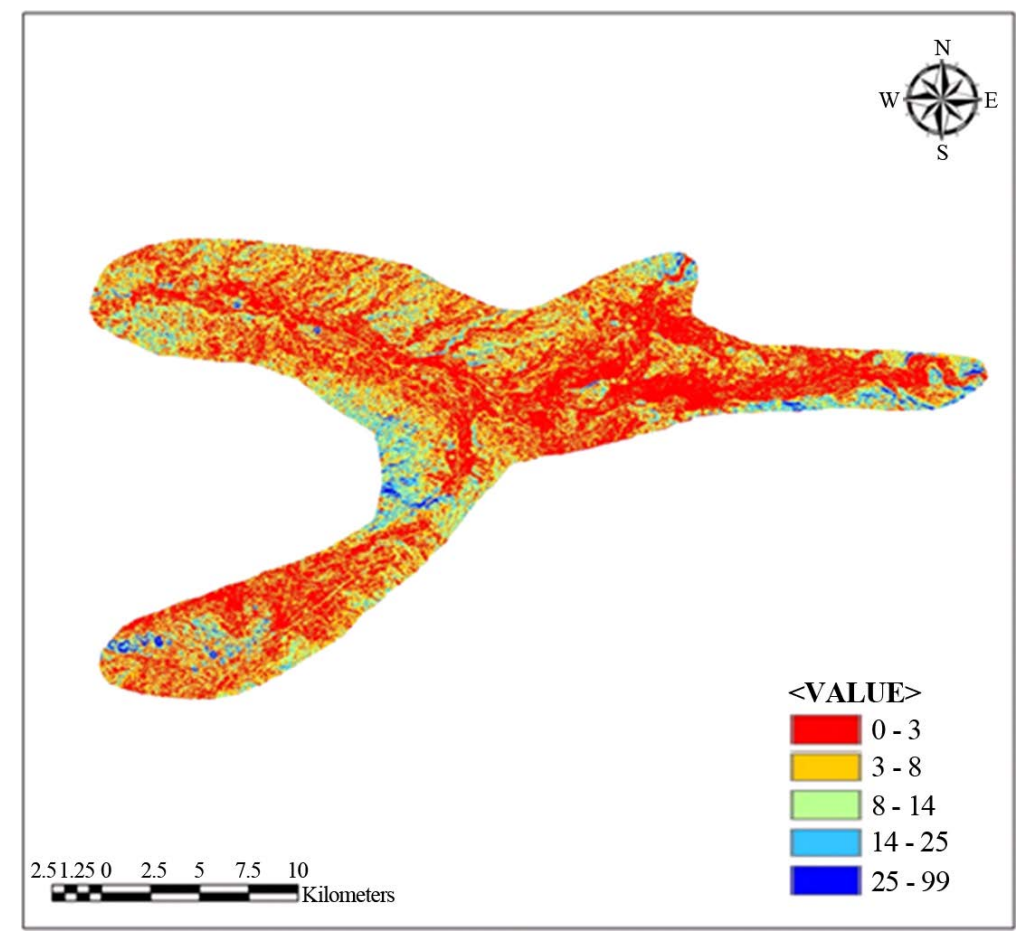

Figure 8. Validated gradient map of the study area. 


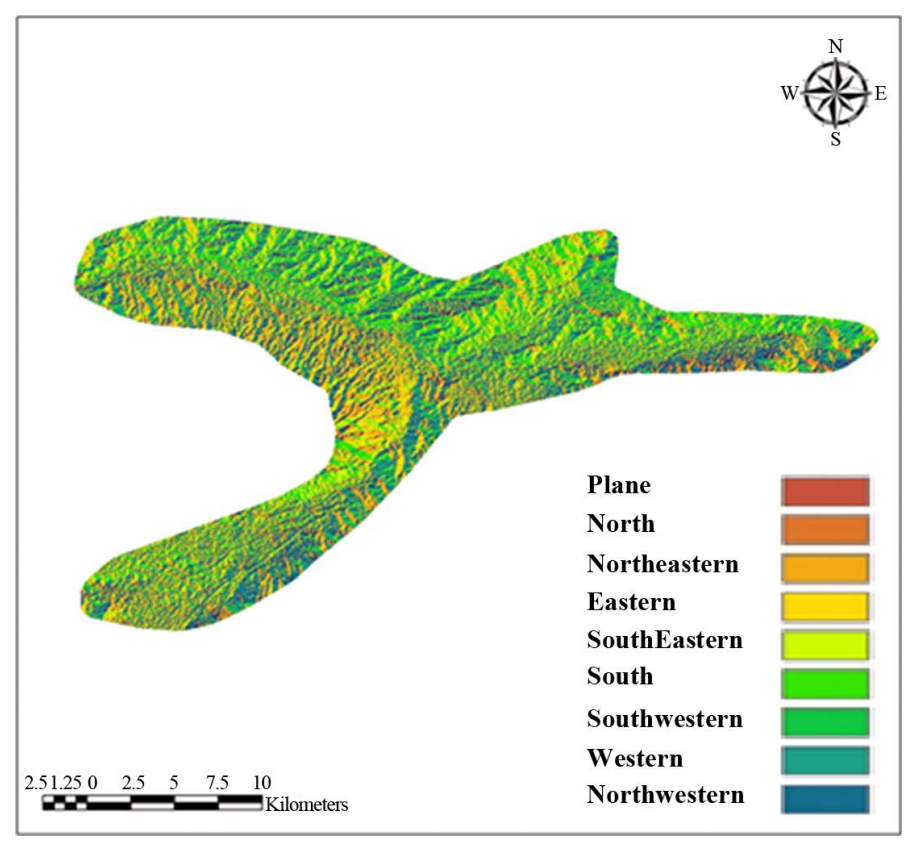

Figure 9. Validated distribution map of slope direction in the study area.

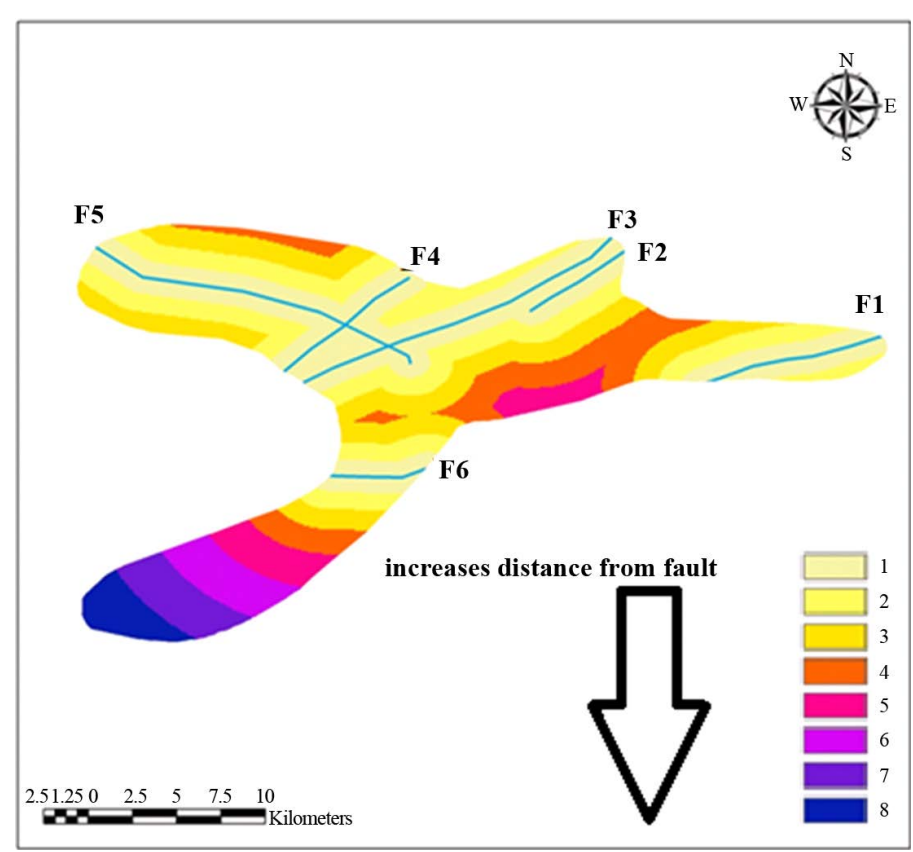

Figure 10. Validated fault map of the study area.

\section{Interpretation of the Final Map of Landslide Hazard Zonation in the Studied Area}

The first glimpse to landslide hazard zonation map, the lack of focus and lack of continuity are obvious and areas with different degrees of risk scattered throughout the map. However, to some extent, we can see certain patterns in the region. As can be seen in the map, the most high-risk areas are concentrated the North, North East and the center of map. These areas have marl and red marl lithology. The dip in this section is from 14 to more than 50 degrees. Western and Southern parts are second dangerous. This section, however, has lower slope, but these deposits (gray shale and Loss) have more instability. 

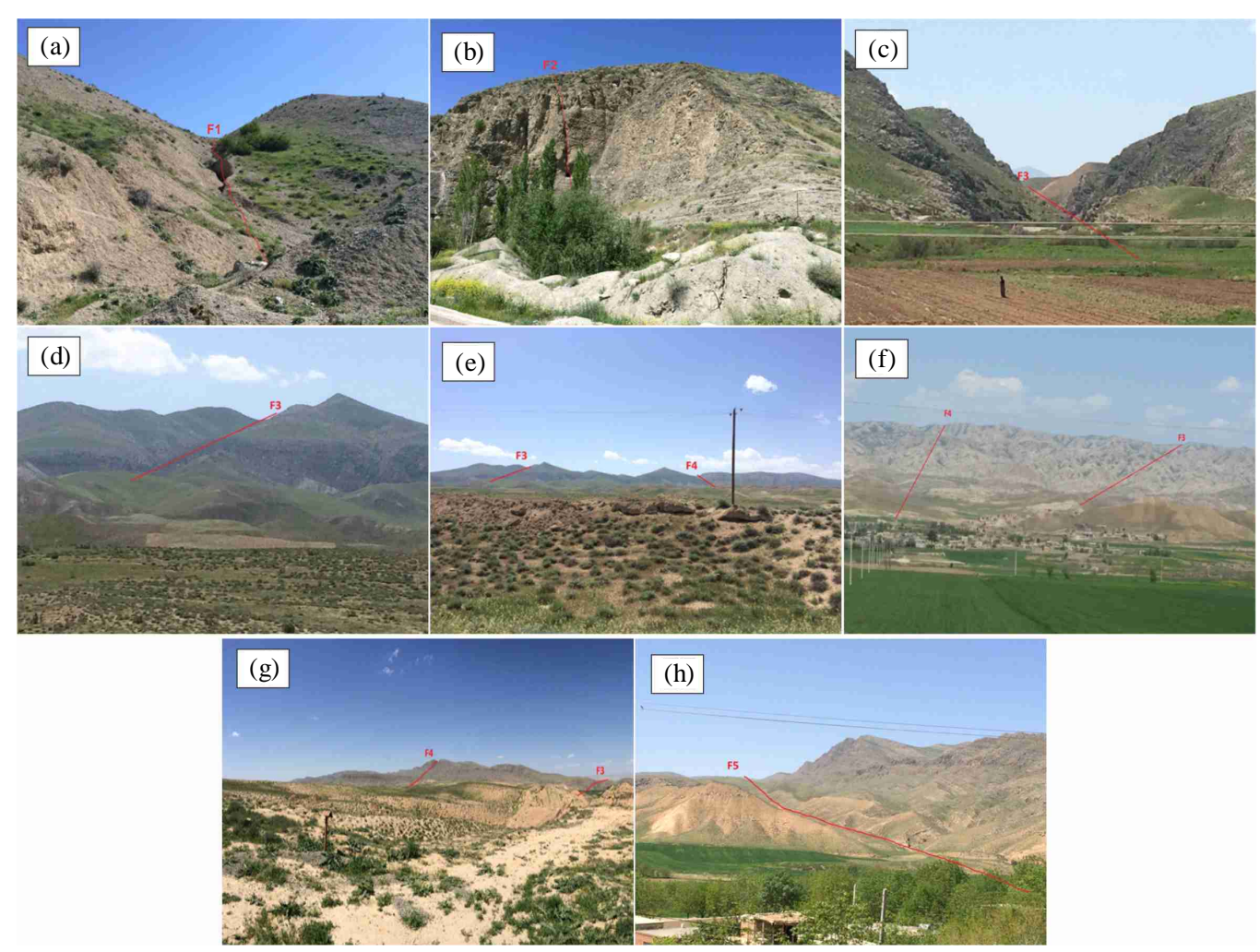

Figure 11. (a) F1 fault view toward north-east; (b) F2 fault view toward north-east; (c) F3 fault view toward south-west; (d) F3 fault view toward south-west; (e) F3 and F4 fault view toward south-west; (f) F3 and F4 fault view toward north-east; (g) F3 and F4 fault view toward north-west; (h) F5 fault view toward north-east.
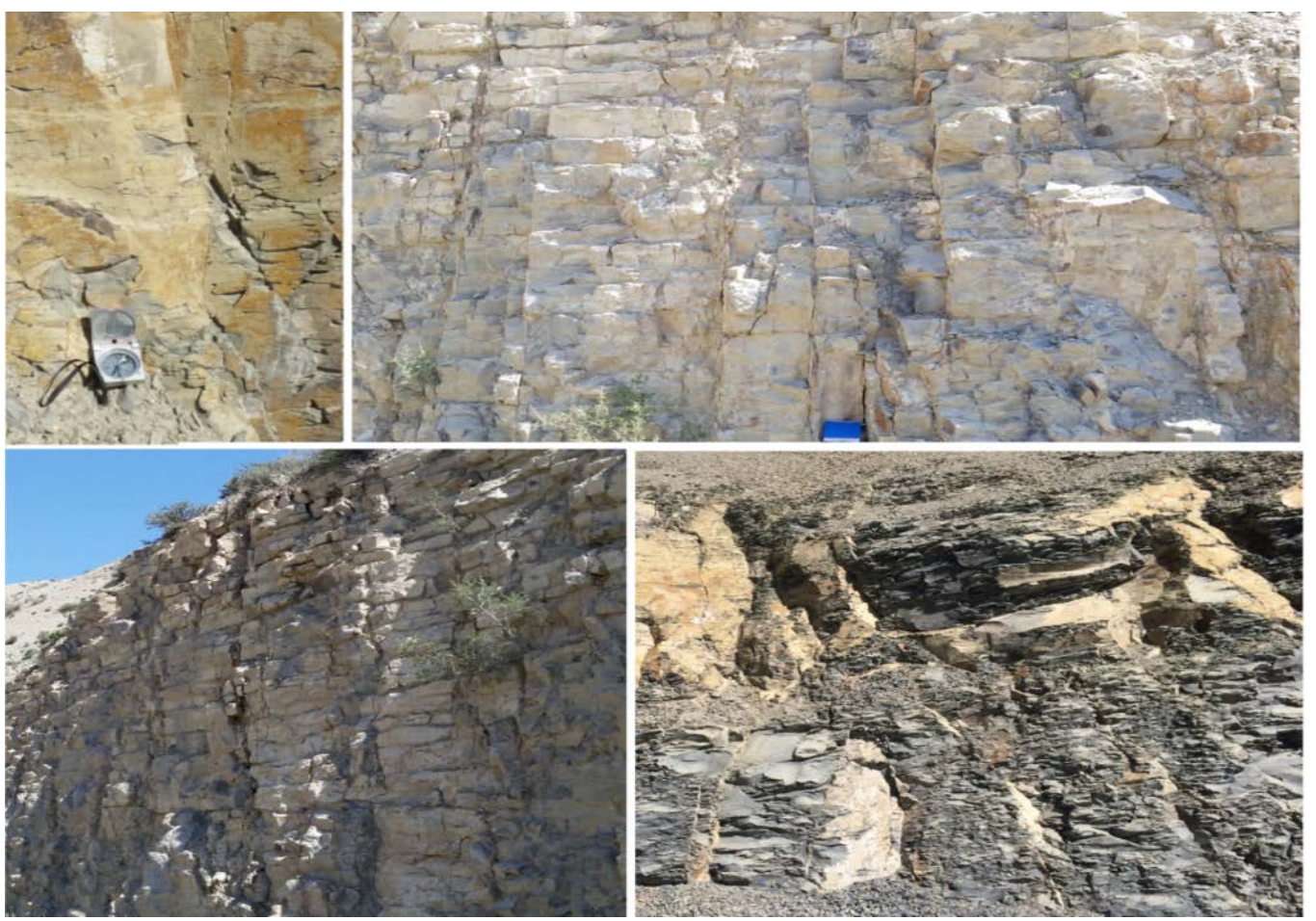

Figure 12. Examples of joints near the some faults. 


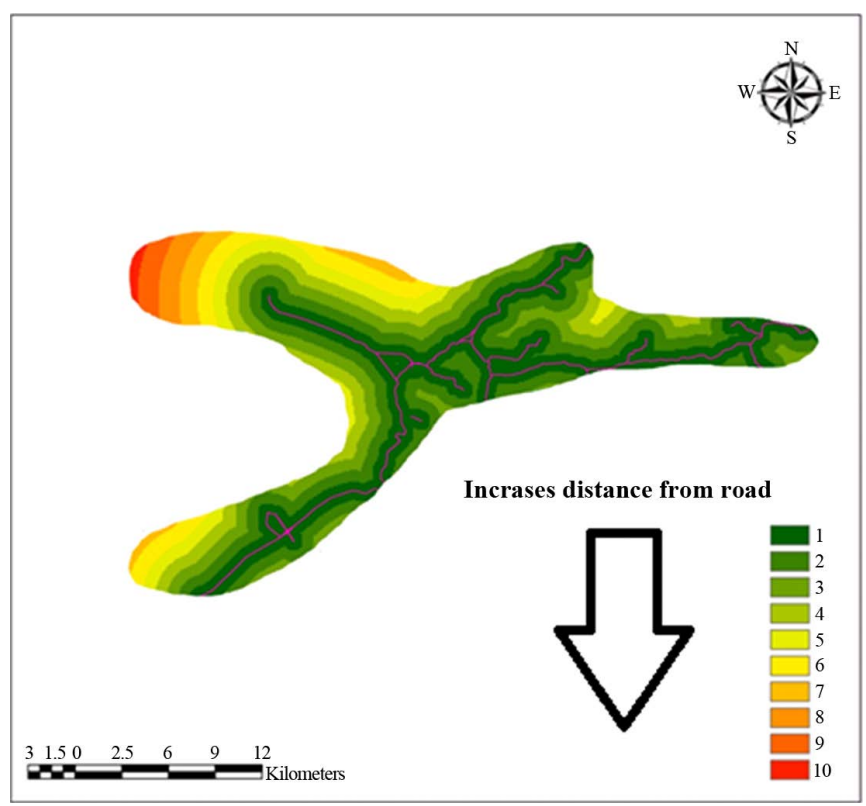

Figure 13. Road map of the study area.

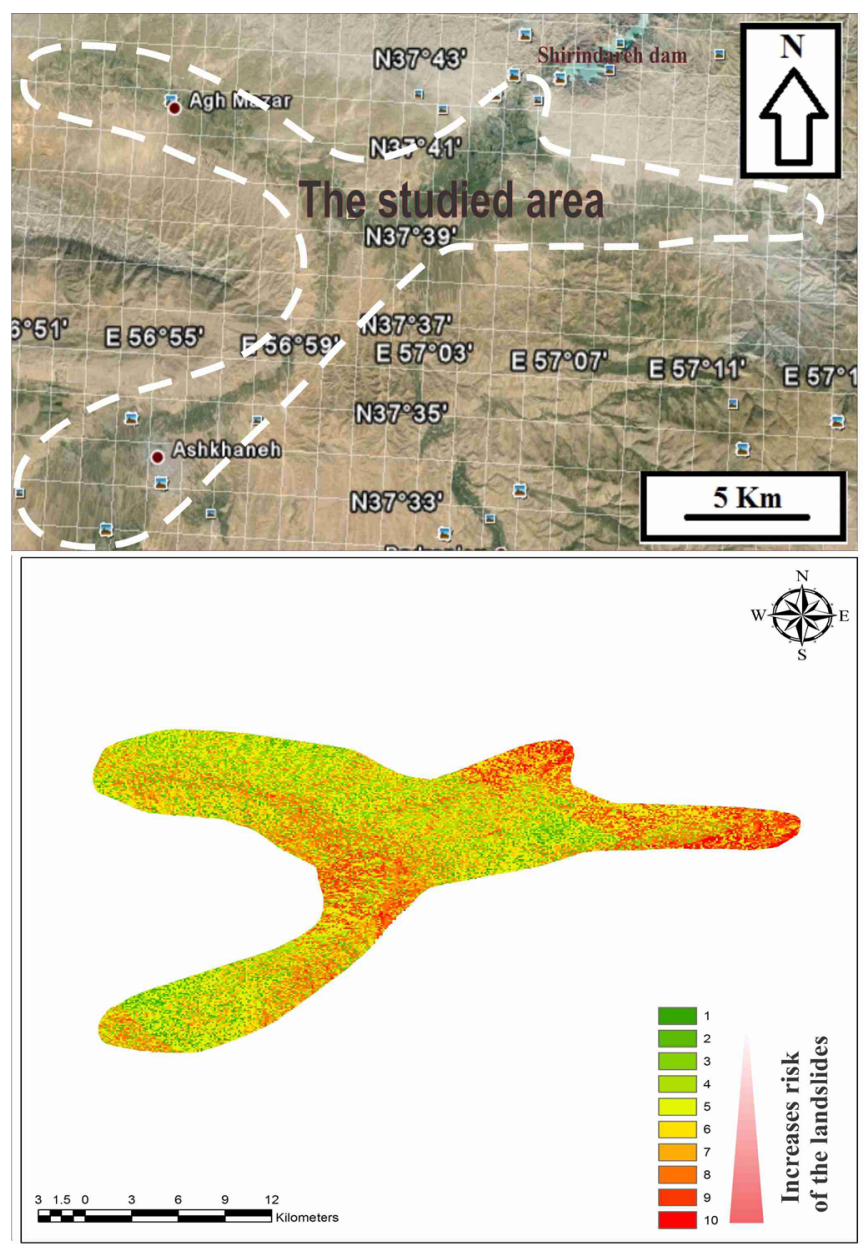

Figure 14. The final map of landslide hazard zonation (down) as well as satellite map (top) area. 


\section{Conclusion}

This study examines the risk of landslides in the area in the province of North Khorasan; after the most important parameters affecting the landslide were identified in the study area, base maps were created. These maps were used as substrate for susceptibility map, validating, and at the end of the final map of the study area were drawn landslide. Two factors - fault (due to low occurrence) and channel (due to drought) - have less effect on risk for landslides. However, the amount (gradient) of slope is most important, and lithology has the second important in the landslide hazard. The final map of landslide hazard zonation study area represents a lack of focus and continuity in different directions of the high-risk is high. Also, areas with various degrees of the risk scattered throughout of the map. Most high-risk areas focused in the north, north east and the center area. In these areas marl and red marl are expanded. The dip in this section is 14 to 50 degrees. Western and southern parts are second hazardous areas.

\section{References}

[1] Nasiri, Sh. (2004) Zoning of Landslides Risk Caused by Earthquake in Northern Tehran. M.S. Thesis, Tarbiad Modares University, $180 \mathrm{p}$.

[2] Salehpour, A. (2001) Survey of Effect Hydromorphic Parameter in the Mass Movement in the Abghuri Drainage Basin Using GIS. M.S. Thesis, University of Tehran.

[3] Ghafouri, M. and Ashouri, A. (1997) Landslide as One of the Natural Disasters in North Khorasan, Iran. Journal of Geographical Research, 445, 90-101.

[4] Ehteramian, K., Mohammadnia Gharaee, S., Rezaiee Azaryani, H., Amjadian, M., Motamedi, M., Gharaee, S. and Rafiee, M. (2013) The Potential of Agro Climatic Zoning of Dry Land Wheat Using GIS in Northern Khorasan Province. International Journal of Agriculture and Crop Sciences, 5, 2598-2609.

[5] Aghanabati, S.A. (2004) Geology of Iran. Geological Survey and Mining Exploration Publications, 586 p.

[6] Ramazani Oomali, R., Shahriari, S., Hafezi Moghaddas, N., Omidi, P. and Eftekharnejhad, J. (2008) A Model for Active Tectonics in Kope Dagh (North-East Iran). World Applied Sciences Journal, 3, 312-316.

[7] Farrokhnia, A.R., Irasteh, S., Pourkermani, P. and Arian, M. (2011) Geo Information Technology for Mass Wasting Hazard Zonation: Central Alborz Iran. Disaster Advances.

[8] Soleymannejad, A. (2013) Survey and Zoning of Unstable Slopes in Extension of 1.100000 Map of Karaj by Emphasizing the Role of Engineering Geology Characteristics. M.S Thesis, Karaj Azad University, 141 p.

[9] Antonini, M., Galli, M., Cacciano, M., Castellani and Salvati, P. (2002) A Geomorphological Approach to Estimate Landslide Hazard and Risk in Urban and Rural Areas in Umbria, Central Italy. Natural Hazards and Earth System Science, 2, 57-72. http://dx.doi.org/10.5194/nhess-2-57-2002

[10] Ahmadi, H., Esmaili, A. and ShariatJafari, M. (2003) Landslide Hazard Zonation Using Multivariate Regression and Analytic Hierarchy Process Methods, Iran. Journal of Natural Resources, 56, 323-336. 